\title{
Oviduct proteins in fertilization and early embryo development
}

\author{
C. D. Nancarrow and J. L. Hill \\ CSIRO Division of Animal Production, Clunies Ross Street, Prospect, NSW, Locked Bag $1_{4}$ \\ Delivery Centre, Blacktown, 2148, Australia
}

\begin{abstract}
The oviduct controls the environment in which the gametes are transported and fuse, and in which embryonic development begins. The ultrastructural topography of the ampulla and isthmus is similar, consisting of ciliated and secretory cells, but a different array of proteins is secreted by each segment along with various serum components. Amino acids are selectively secreted by the oviduct; these amino acids probably interact with the gametes or embryo to facilitate the processes of fertilization and development. An oviduct-specific glycoprotein is synthesized by the ampulla of sheep and cattle in response to oestrogen and secreted mainly from day -1 to day 3 of the ovarian cycle. This oestrus-associated glycoprotein (EGP) has a variable molecular mass of $80-97 \mathrm{kDa}$ and a $\mathrm{pI}$ value ranging from 4.7 to 5.5 . The bovine (b) and ovine (o) EGP genes are $95.5 \%$ identical and consist of 1560 base pairs encoding 519 amino acids containing one $N$-linked and several $O$-linked glycosylation sites. The terminal glycosides are $N$-acetylglucosamine and galactose$\mathrm{N}$-acetylgalactosamine for bEGP, and fucose, galactose and sialic acid residues are also identified for oEGP. EGP binds to zona pellucida and blastomere membranes, but evidence for EGP binding to sperm membranes is equivocal. After in vitro fertilization the proportion of sheep oocytes cleaving was increased in the presence of oEGP, but when single-cell embryos were cultured with oEGP, these cleavage rates were reduced. In addition, consistent positive effects of oEGP were observed on blastocyst formation. Elaboration of the mechanism of synthesis of EGP, its action and its role in fertilization and embryo development is important for our understanding of the events of early pregnancy.
\end{abstract}

\section{Introduction}

The ruminant oviduct is essential for gamete transport, fertilization and embryo transport and provides an environment for the early development of embryos. Apart from transport and the provision of a medium for culture in vivo, it is still uncertain whether any specific components secreted by the oviduct are essential for fertilization and early embryo development. The strongest candidates for the latter function are vitamins, amino acids, growth factors and proteins. Both vitamins and amino acids are supplied in conventional culture media or in serum additives to these media and when such artificial media are used in oocyte maturation in vitro, fertilization and culture, resultant embryos can implant in surrogate dams and give rise to offspring. This fact indicates that the provision of growth factors and specific proteins by the oviduct is not obligatory to fertilization and embryo development. However, the occurrence of extended gestation duration, increased lambing masses and lamb mortality (Walker et al., 1992) associated with cultured or micromanipulated embryos does suggest that there may be facilitative actions of oviductal components and that these components should be included in culture media for optimal development. 


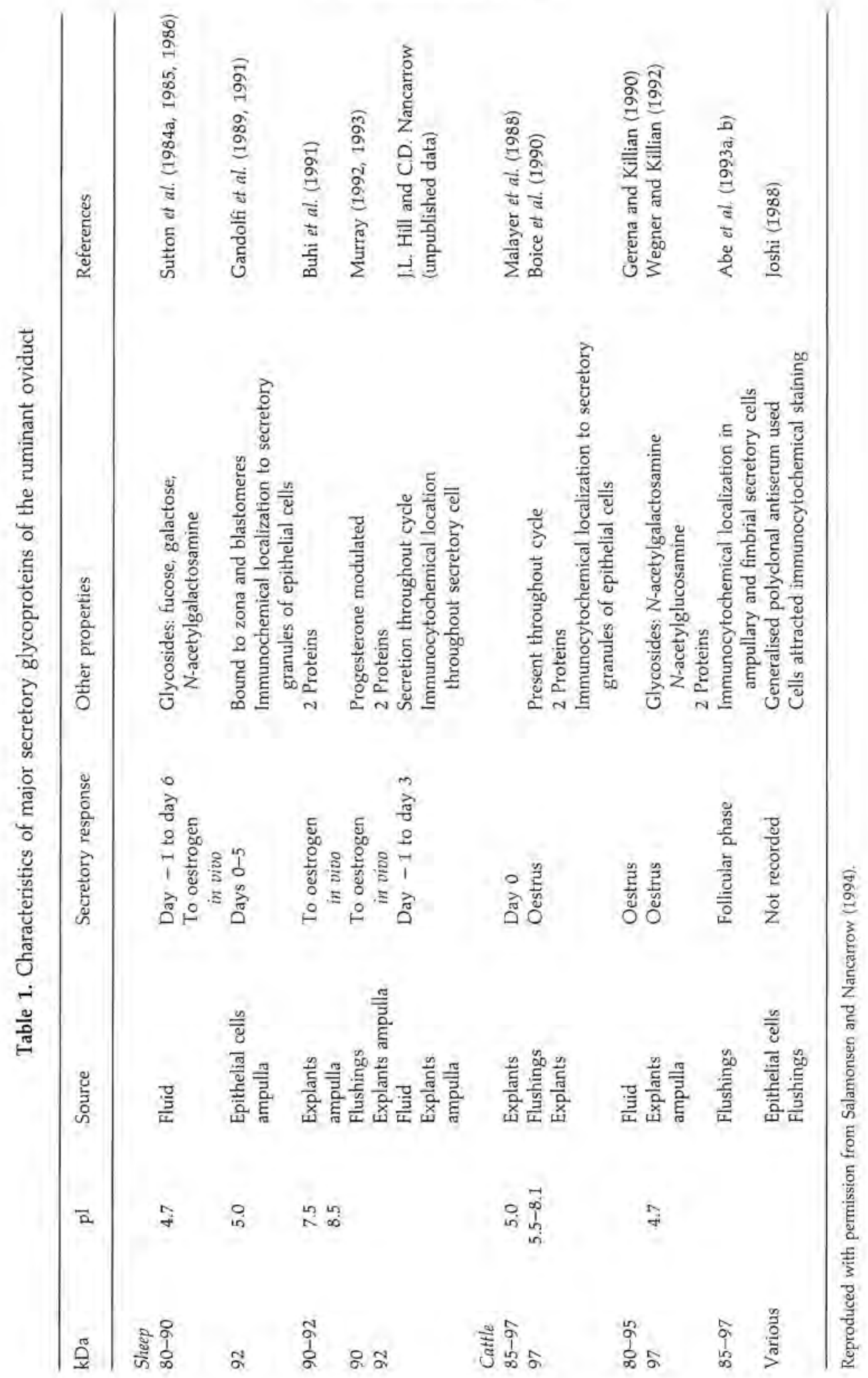


Several proteins have been identified as oviduct specific and the oestrus-associated glycoprotein first identified in sheep (oEGP) by Sutton et al. (1984a) and a similar glycoprotein described in cattle (bEGP) by Malayer et al. (1988) have been studied most thoroughly. Humans, baboons and pigs secrete similar proteins and these, together with oEGP and bEGP, represent a group with potentially similar function (Salamonsen and Nancarrow, I994). While this review will present current knowledge about the biology of EGP in ruminants, we do not wish to overlook the possible developmental importance of growth factors and their receptors, which may be provided by the oviduct or the developing embryo (Watson et al, 1994a). Demonstrations that amino acids are secreted in oviduct fluid at quite different concentrations from those in plasma (Nancarrow et al, 1992) and that amino acids together with bovine serum albumin provide an exceptional culture medium (Moore and Bondioli, 1993; Gardner et al., 1994; Walker et al., 1995) provide strong evidence for the contention that the oviduct maintains an optimal environment for fertilization and embryo development.

\section{Synthesis and Secretion of EGP}

The secretion of EGP has been the subject of several studies using different techniques and sources of oviduct proteins (Table 1). Initial studies reported a molecular mass of $80-90 \mathrm{kDa}$ for oEGP in ovine oviductal fluid (Sutton et al., 1984a) when analysed on SDS-PAGE gels and $92 \mathrm{kDa}$ (Gandolfi et al., 1989) for ${ }^{35} \mathrm{~S}$-labelled oEGP produced by oviduct epithelial cells in vifro. We found at that time that oEGP was present in the oviduct lumen as a very large conglomerate or multimer, able to be reduced to its monomeric form by reduction with mercaptoethanol, and proposed that it binds to ova whereby it facilitates fertilization and embryo development (Sutton et al. 1984b). oEGP is excluded from most fractionating gels but Sephacryl ${ }^{\mathrm{R}} \mathrm{S}-400$ (Pharmacia LKB, Uppsala) with an exclusion of $8000 \mathrm{kDa}$ has been used to demonstrate that the native $M_{r}$ of the protein is about $4000 \mathrm{kDa}$. The broad, diffuse $M_{r}$ range following denaturing electrophoresis was attributed to variability in the pattern of glycosylation (Sutton et al., 1984a). In oitro incorporation studies have suggested the presence of two oestrusassociated glycoproteins in ewes, one with an $M_{\mathrm{r}}$ of $90 \mathrm{kDa}$ and the other of $92 \mathrm{kDa}$ (Buhi ef al, 1991), although only one protein of 90-92 kDa was found by Murray $(1992,1993)$. Several studies in cattle support secretion of a pair of proteins (Table 1).

The protein of cattle has a slightly greater molecular mass $(80-97 \mathrm{kDa})$ but a similar acidic pl value to that of oEGP (Table 1). For sheep and cattle, the greatest concentration of EGP was found in oviduct Fluid collected at or just after oestrus (Sutton et al., 1984a; Gerena and Killian, 1990) or in conditioned media from cultures of epithelial cells (Gandolfi et al., 1989) or tissue explants (Malayer ef al., 1988; Boice et al., 1990; Buhi ef al. 1991; Murray, 1992; Wegner and Killian, 1992) taken on day 0 of the cycle or after oestrogen induction of ovariectomized animals.

When oviductal fluid was sampled daily during the ovarian cycle and oEGP detected using a monoclonal antibody (MAC 264) raised against the culture-derived oEGP (sOP 92: Gandolfi et al., 1989), it became obvious that oEGP is secreted throughout, but in a cyclic manner (J. L. Hill and C. D. Nancarrow, unpublished). A western blot gave similar patterns when the monoclonal antibody or soy bean agglutinin was used in detection (Fig. 1). The latter recognizes both terminal galactosyl (Gal) and $N$-acetylgalactosamine (GalNAc) residues on glycoproteins. This study confirmed the previous findings and showed that the concentration of oEGP in oviduct fluid is much higher during the active secretory phase (days - I to 3 ).

Analysis of conditioned medium from whole explant cultures showed that EGP is secreted by the ampullary region of the oviduct in sheep and cattle (Table 1). In some experiments, the infundibulum of sheep and cows was shown to contain or synthesize EGP (Murray, 1992; Abe et al., 1993b). Hollis ef al. (1984) suggested that the secretory granules that accumulate in the secretory cells toward oestrus are the source of oEGP but could not clearly establish a secretory pattern for these granules. Gandolfi et al. (1991), in sheep, and Boice et al. (1990) and Abe et al. (1993b), in cattle, demonstrated an accumulation of EGP-specific immunogold particles over these granules. Immunofluorescent studies on sections of oviducts taken from cyclic ewes demonstrated that the antigen is present in the secretory cells of the ampulla throughout the cycle (Fig. 2) and is prominent in apical protrusions of these cells just before 
available to glycoproteins leading to considerable functional specificity and the resultant diversity of differentiation of organisms (see review by Varki, 1993). A few glycoproteins constitute the zona pellucida and others are present on sperm surfaces and take part in sperm-egg binding mechanisms perhaps associated with the glycosyltransferases (Shur and Hall, 1986; Wassarman, 1994). Oviductal glycoproteins such as EGP may therefore interact and be involved in the process of fertilization in mammals.

Terminal glycosides are identified by specific lectin binding to proteins transferred to nitrocellulose membranes after SDS-PAGE electrophoresis. Glycosides of oEGP were initially described as Gal, GalNAc, fucose and the dimeric galactosyl ( $\beta 1,3) N$-acetylgalactosamine (Gal-GalNAc) (Sutton et al., 1985). Although wheat germ agglutinin (WGA) bound to oEGP in this experiment, this does not constitute irrefutable proof of identity of the sugar moieties as it could not be completely displaced by

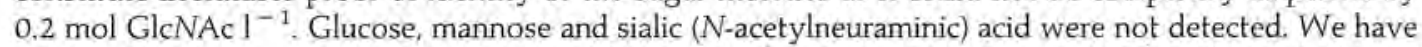
now found that a combination of $0.4 \mathrm{~mol} \mathrm{GlcNAc}^{-1}$ and $0.2 \mathrm{~mol}^{-1}$ sialic acid $\mathrm{l}^{-1}$ inhibits binding of WGA, suggesting that both of these glycosides are represented on oEGP. Gal-GalNAc and GlcNAc were reported to be present in bEGP, and WGA binding was completely inhibited by $0.5 \mathrm{~mol}$ GIcNAc $1^{-1}$ (Wegner and Killian, 1992). Perhaps this indicates species differences in the function of ovine and bovine EGP. Murray (1993) found that labelled GleNAc incorporation in cultured ampullary explants was decreased, or inhibited, in explants taken during the progestational phase and suggested that there is endocrine control over glycosylation of the core protein. This requires further investigation.

The need to characterize these terminal glycosides is important for an understanding of how EGP acts and what form of EGP is best to use in in vitro fertilization and in vitro culture media if a positive effect on fertilization and embryo development can be demonstrated. A source of EGP will be needed and this could be provided through genetic engineering. Glycosylation patterns of recombinant glycoproteins are unpredictable, but there are specific interactions between the type of glycosylation pattern favoured by the host cell, the glycotype, and the individual polypeptide (Warren, 1993). However, modifications to established glycosylation patterns usually reduce bioactivity in vivo. These aspects need to be considered when production of oEGP is directed by transfection of recombinant genes into cultured mammalian cells and production of transgenic animals.

\section{Molecular Characterization of EGP}

Molecular cloning techniques are necessary for the production of sufficient quantities of purified oEGP to determine whether it plays a role in fertilization or embryo growth and subsequent development. There are questions that relate to the action of oestrogen in initiating the sequence of events in the synthesis of oEGP (Salamonsen and Nancarrow, 1994) that could be answered using molecular probes. The gene sequence for the bEGP has recently been published (Sendai ef al., 1994) and we have used this information to initiate cloning procedures for oEGP. The bovine sequence consists of 1612 base pairs (bp) coding for a protein with 537 amino acids. However, the first 18 amino acids of the amino-terminal end represent a partial signal sequence, the core protein consisting of 519 amino acids with an estimated molecular mass of $57.684 \mathrm{kDa}$. The human glycoprotein in contrast has a higher molecular mass and its open reading frame is 1962 bp encoding 633 amino acids with a predicted molecular mass of $70.5 \mathrm{kDa}$ (Arias et al., 1994). Bovine EGP contains one $\mathrm{N}$-glycan site and numerous potential O-glycan sites; Arias et al. (1994) found four potential N-glycan sites for the human protein. Hence the increase in molecular mass of the glycoprotein from 95 to $120 \mathrm{kDa}$ between humans and cows appears to be attributable to the larger molecular mass of the core protein $(57.7$ to $70.5 \mathrm{kDa})$ and to an increase in $N$-glycosylation.

There is high sequence similarity between these proteins, accounting for the similar physiological characteristics so far described. The $3^{\prime}$ cDNA end of the human sequence exhibits $92 \%$ identity with 1195 nucleotides from the partial cDNA sequence of baboons (Donnelly et al., 1991) and a 91\% amino acid identity. Sequence similarity of the 534 amino acids of humans and cows was less at $72.5 \%$, whereas that between cows and baboons was $71 \%$ (Sendai et al., 1994). Identity between the $1560 \mathrm{bp}$ of the oEGP gene and the bEGP sequence was $95,5 \%$ (J. T. A. Marshall, A. G. Brownlee and C. D. Nancarrow, unpublished). 
Preliminary investigation of expression of the genes using probes for mRNA have confirmed that both the bovine and baboon genes are responsive to oestrogen (Sendai et al., 1994; Arias et al., 1994). These authors reported that, in progesterone-dominated tissues taken from the dioestrous phase of the bovine cycle or early follicular and postpartum stages of baboons, amounts of mRNA were lower. This may reflect the lack of oestrogen at these stages rather than a suppressive effect on expression by progesterone, for oEGP is always secreted in high concentrations in response to oestradiol, regardless of the progestational status of the ewes (Sutton et al., 1986; Salamonsen and Nancarrow, 1994).

\section{EGP Binding to Spermatozoa}

In many species, oviductal oestrus-associated glycoproteins bind to oocytes and embryos (see Salamonsen and Nancarrow, 1994) but equivocal reports have been published on the binding of these proteins to spermatozoa. There are specific binding sites for spermatozoa on the zona pellucida (Gwatkin, 1977; Yanagimachi, 1981; Dunbar, 1983; Hartman, 1983) and critical roles have been identified for zona pellucida proteins, $Z \mathrm{P} 3$ and $\mathrm{ZP2}$, in sperm binding in mice (Wassarman, 1994). It is possible that oviductal glycoproteins are also involved in the interaction of recognition proteins and species-specific binding of gametes that facilitate fertilization.

Evidence for the binding of oviduct proteins to spermatozoa is accumulating. Some of these reports indicate that EGP might participate in this binding (Voglmayr and Sawyer, 1986; Lippes and Wagh. 1989; McNutt ef al, 1992; King and Killian, 1994) and proteins of similar size have been extracted from sperm membranes. Both Sutton et al. (1984b) and King and Killian (1994) found that labelled oviduct proteins bind to ram and bull spermatozoa, and King and Killian reported that the molecular mass of the major component was 90-95 kDa. Voglmayr and Sawyer (1986) found that a variety of uterine and oviduct proteins accumulated on membranes of spermatozoa during passage to the site of fertilization. Other data indicate that several bovine oviductal proteins bind to spermatozoa including an $85-95 \mathrm{kDa}$ glycoprotein, but the presence of bEGP could be detected only after permeabilization of the membranes with deoxycholate (King and Killian, 1994). Reuter ef al. (1994), using an immunofluorescence assay with a polyclonal antiserum and immunoblotting after solubilizing the membranes, found that the human equivalent to oEGP (called oviductin or huOGP; hEGP) did not bind to human spermatozoa. In contrast, Lippes and Wagh (1989) demonstrated localized binding of a $54 \mathrm{kDa}$ glycoprotein to the human sperm head. The molecular mass of this protein (human oviductin I) is more in keeping with that of non-glycosylated core proteins of EGP, although it may represent a dissimilar protein, However, hEGP bound to hamster oocytes and a uterine glycoprotein bound to human spermatozoa under the same conditions. When testing capacitated and uncapacitated sheep spermatozoa incubated in vitro or in vivo, we could not observe specific immunofluorescence greater than that found in negative controls (Fig. 3). Positive staining was found for oviduct epithelial cells, embryos and follicular oocytes incubated in oviduct proteins. The interpretation of the previous data as true physiological evidence for EGP binding to spermatozoa must therefore be questioned. Sutton et al. (1984b) reported degradation of proteins after incubation with spermatozoa at $37^{\circ} \mathrm{C}$. Perhaps spermatozoa do degrade EGP and other oviduct proteins allowing the products to enter or pass through the membranes and this may account for the data presented by Sutton et al. (1984b) and King and Killian (1994).

There is high sequence similarity between the ovine and bovine genes indicating that the size and nature of non-glycosylated core proteins are similar. There appear to be some differences between the glycosyl residues of each, with the oEGP chains terminating in fucose, sialic acid and GalNAc in addition to the Gal-GalNAc and GlcNAc reported for cows (Wegner and Killian, 1992). Nevertheless, differences in glycosylation patterns, lengths and branching of chains and number and nature of $\mathrm{N}$-and $\mathrm{O}$-linked glycosylation sites might result in different membrane binding properties, or there may be differences between the sperm membranes of different species.

\section{Role of EGP in Fertilization}

Oviduct-specific glycoproteins bind to the zona pellucida of oocytes and spermatozoa of several species implying a role for these proteins in fertilization or early embryo development (Gandolfi ef al., 1991; 

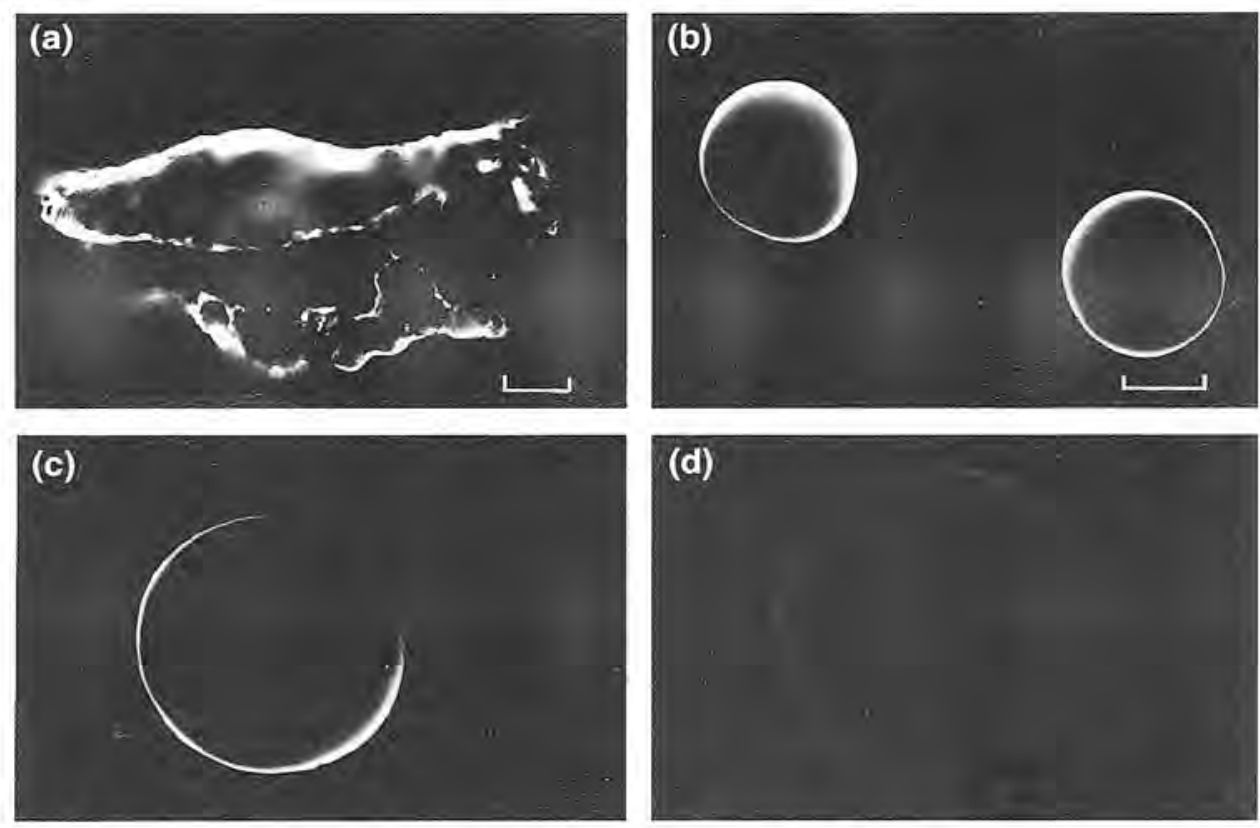

Fig. 3. Binding of ovine oestrus-associated glycoprotein (oEGP) to gametes. Three experiments were carried out in which oEGP binding to spermatozoa was tested. In the first, freshly collected and washed spermatozoa were incubated with and without oviduct fluid and fractions F1 and F2 for various times up to $12 \mathrm{~h}$. F1 is the first fraction eluted from a Superose 12 FPLC column (Pharmacia, Piscatawy, NS) and contained oEGP while the second (F2) was predominantly albumin. Proteins from $0.5 \mathrm{ml}$ thawed oviduct fluid were eluted with $50 \mathrm{mmol}$ sodium phosphate $1^{-1}(\mathrm{pH} 7.2)$ containing $150 \mathrm{mmol} \mathrm{NaCl} \mathrm{I}^{-1}$. Fractions were freeze dried, reconstituted in synthetic oviduct fluid (SOF) then dialysed against SOF for $36 \mathrm{~h}$ before use in culture. In the second, capacitated spermatozoa collected after swim-up were incubated as in the first experiment. The third experiment examined the binding of oEGP to spermatozoa in vivo, following intra-uterine insemination of freshly collected and diluted semen. Spermatozoa were recovered from different locations within the reproductive tract $2-6 \mathrm{~h}$ after intrauterine insemination. The presence of oEGP was determined as described in Fig. 2. Freshly collected (a) oviduct epithelial cells, (b) oviductal embryos, and follicular oocytes incubated in (c) the presence or (d) the absence of F1 were used as positive $(a, b, c)$ and negative (d) controls. No difference between the negative control, untreated and FI-treated spermatozoa could be detected; no fluorescence was detected in either preparation.

Wegner and Killian, 1991; Boice et al., 1992; King and Killian, 1994). As discussed above, evidence for a role of oEGP in fertilization by direct sperm binding is equivocal. We examined the effects of including oEGP in various IVF media (J. L. Hill, S. K. Walker, G. H. Brown and C. D. Nancarrow, unpublished). The basic IVF medium consisted of a synthetic oviduct fluid (SOF, Tervit et al., 1972) either supplemented or not supplemented with human serum or sheep serum. Various amounts of a high molecular mass oEGP-enriched fraction (F1, see Fig. 3) were added to these media. In the absence of serum, fertilization, determined by the number of embryos undergoing first cleavage, was poor. Both the proportion of embryos undergoing their first cleavage and their developmental competence were significantly greater when IVF occurred in the presence of sheep serum. However, F1 added to the medium containing human serum significantly increased the proportion of cleaved embryos and the specificity of this effect was confirmed in a study in which BSA used at comparable protein concentrations to FI failed to elicit the same positive effect. Only at a concentration of 10\% did F1 increase fertilization rates in media supplemented with sheep serum. Overall, the use of F1 in fertilization medium was advantageous to the developmental competence of the resulting embryos. These data imply that there are components in sheep serum that are essential to fertilization and these might also 
be present in oviduct secretions and F1. Ovine EGP cannot be detected in serum using western blot techniques (J. L. Hill and C. D. Nancarrow, unpublished); so that although F1 improved fertilization rates in the medium containing human serum, we cannot conclude unequivocally that EGP plays a role in fertilization in ruminants.

\section{Embryo Coculture with Oviduct Epithelial Cells}

There have been many attempts to improve the quality of embryo development by coculturing in the presence of a variety of cell types. Monolayers of oviduct epithelial cells have usually been used (see review by Nancarrow and Hill, 1994). There are two principles involved. First, cells, and in particular oviduct cells that are normally juxtaposed to early developing embryos, were thought to provide one or a range of substances that might be beneficial or even critical to development. Second, these cells might act as scavengers and absorb or metabolize embryotoxic components from the various media. In some instances, conditioned media from these cell cultures have been used. In general, development past the early blocks to cell division occurs and improved hatched blastocyst rates can be obtained, particularly in conditions of higher oxygen content, but still at suboptimal rates (Nancarrow and Hill, 1994; Watson et al, 1994b). Glycine and alanine are used by embryos (Moore and Bondioli, 1993; Gardner ef al., 1994) and they are present in oviduct fluid at far greater concentrations than in culture media (Nancarrow et al., 1992). In addition, the oviduct-specific oEGP is absent from most coculture media because synthesis and release of oEGP ceases during the 3-6 days of formation of the monolayer. Nancarrow and Hill (1994) concluded that embryo coculture might be compromised by the absence of stromal cells to mediate oestrogen induction of embryotrophic glycoproteins in epithelial cells and by too low concentrations of certain amino acids. Clearly a balance has to be reached in any culture system in that deamination of amino acids produces embryotoxic concentrations of ammonium ions (Gardner et al., 1994), at least in the absence of somatic cells.

\section{Role of oEGP in Embryo Development}

Recent studies in our laboratory have examined the effect of oEGP (FI) on embryo development from fertilization or the first cleavage stage through to hatched blastocysts (J. L. Hill, S. K. Walker, G. H. Brown and C. D. Nancarrow, unpublished). Incorporation of FI into SOF supplemented with $20 \%$ human serum was used to examine the effects of oEGP on development abnormalities that have resulted from this culture medium (Walker ef al, 1992). A second fraction of oviduct fluid (F2) containing mainly albumin was used as a control in the study. The addition of FI resulted in a reduced cleavage rate of one-cell embryos flushed from the oviducts of superovulated ewes but a greater number of nuclei in newly formed blastocysts and a delay in the time taken for blastocyst formation. These effects tend to redress the influence of culture in vitro, compared with developmental rates in vivo (Walker et al., 1992).

These experiments were repeated using embryos produced in vilro and compared four different concentrations of F1 $(0-20 \%$, v/v) (J. L. Hill, S. K. Walker, G. H. Brown and C. D. Nancarrow, unpublished). Results confirmed previous effects of the presence of FI in the culture medium: the proportion of embryos cleaving was reduced and the proportion of cleaved embryos forming blastocysts increased. However, the day of blastocyst formation was not delayed and only in the blastocysts forming first on day 4 were there more nuclei. The consistent decrease in the number of embryos undergoing first division in the presence of FI suggests that this oEGP-containing fraction may be involved in a process of selection. Culture of sheep embryos in control medium (SOF plus human serum) permits a greater proportion of embryos to develop to blastocysts than occurs in vivo (Walker et al., 1992), perhaps supplanting a mechanism in vivo that eliminates impaired embryos. The inclusion of FI in IVF medium but not in culture medium resulted in an increase in the proportion of oocytes cleaving (J. L. Hill, S. K. Walker, G. H. Brown and C. D. Nancarrow, unpublished), implying more than one role for EGP: one facilitating fertilization followed by a second involvement in a selection mechanism before first cleavage. Overall, these experiments consistently showed that the oEGP-enriched additive 
positively affected cell division in a number of ways resulting in blastocysts that appear comparable to those developed in vivo.

\section{Conclusions}

A specific oestrus-associated glycoprotein is synthesized by ruminant ampullary secretory cells in response to the pro-oestrous surge of oestrogen and secreted into the oviduct lumen at about the time of ovulation and fertilization. Although at least two forms of this protein have been described, only one gene has been cloned for both cattle and sheep, and these display a high degree of identity. Nevertheless, there are some glycosylation differences that might account for possible differences in sperm binding characteristics. The role of this glycoprotein has not been elucidated, but it binds to zona pellucida and blastomere membranes and in culture appears to regulate cell division and blastocyst formation rates. Although it does not appear to be obligatory for fertilization or embryo development, it may act in a facilitatory role and in its pure form be a useful component of embryo production media in vitro.

The authors would like to thank our colleagues, C. Pruss, P. Mitchell, A. Dafter, J. Marshall and A. Brownlee for their various contributions to this work. We are most grateful for the professional collaboration of S. Walker and G. Brown in much of the original work presented here. This study was partially funded (JLH) by the Australian Wool Research and Promotion Organization. now the International Wool Secretariat.

\section{References}

Abe H. Numazawa Ci Abe M, Hoshi H and Oikawa T (1993a) Production and characterization of monoclonal antibodies specific for bovine oviductal glycoproteins Journal Experimental Zoology 265 77-83

Abe H, Numazawa C, Abe M, Onodera M and Katsumi A (1993b) Immunocytochemical localization of oviduct-specific glycoproteins in the oviductal epithelium from cows at follicular and luteal phases Cell and Tissue Research 274 4t-47

Arias EB, Verhage HG and Jaffe RC (1994) Complementary deoxyribonucleic acid doning and molecular characterization of an estrogen-dependent human oviductal glycoprotein Biology of Reproduction 51 685-694

Boice ML, Geisert RD, Blair RM and Verhage HG (1990) Identification and characterization of bovine oviductal glycoproteins synthesized at estrus Biology of Reproduction $43 \quad 457-465$

Boice ML, Mavrogianis PA, Murphy CN, Prather RS and Day BN (1992) Immunocytochemical analysis of the association of bovine oviduct-specific glycoproteins with early embryos Joumal of Experimental Zoology 263 225-229

Buhi WC, Bazer FW, Alvarez IM and Mirando MA (1991) In vitro synthesis of oviducal proteins associated with estrus and $17 \beta$-estradiol-treated ovariectomized ewes Endocrinology 128 3086-3095

Donnelly KM, Fazleabas AT, Verhage HG, Mavrogianis PA and Jaffe RC (1991) Cloning of a recombinant complementary DNA to a baboon (Papio anubis) estradiol-dependent oviduct-specific glycoprotein Molecular Endocrinology 5 356-364

Dunbar BS (1983) Morphological, biochemical and immunochemical characterization of the mammalian zona pellucida. In Mechanism and Control of Animal Fertilization PP 139-175 Ed. JF Hartman. Academic Press, New York
Gandolfi F, Brevini TAL, Richardson L, Brown CR and Moor RM (1989) Characterization of proteins secreted by sheep oviduct epithelial cells and their function in embryonic development Development 106 303-312

Gandolfi F, Modina S, Brevini TAL, Galli C, Moor RM and Lauria A (1991) Oviduct ampullary epithelium contributes a glycoprotein to the zona pellucida, perivitelline space and blastomere membrane of sheep embryos European Joumal of Basic and Applied Histochemistry 35 383-392

Gardner DK, Lane M, Spitzer A and Batt P (1994) Enhanced rates of cleavage and development for sheep zygotes cultured to the blastocyst stage in vitro in the absence of serum and somatic cells: amino acids, vitarnins and culturing embryos in groups stimulate development Biology of Reproduction 50 $388-400$

Gerena RL and Killian GJ (1990) Electrophoretic characterization of proteins in oviduct fluid of cows during the estrous cycle fournal of Experimental Zoology 256 113-120

Gwatkin RBL (1977) Fertilization Mechanisms in Man aud Mammals Plenum Press, New York

Hartman JF (1983) Mammalian fertilization: gamete surface interactions in vitro. In Mechanism and Control of Animal Fertilization pp 325-364 Ed. IF Hartman. Academic Press, New York

Hollis DE, Frith PA, Vaughan ID, Chapman RE and Nancarrow CD (1984) Ultrastructural changes in the oviductal epithelium of Merino ewes during the estrous cycle American Joumal of Anatomy $171441-456$

Joshi MS (1988) Isolation, cell culture and immunocytochemical characterization of oviduct epithelial cells of the cow Joumial of Reproduction and Fertility 83 249-261

King RS and Killian GJ (1994) Purification of bovine estrusassociated glycoprotein and localization of binding on sperm Biology of Reproduction 51 34-42 
Lippes I and Wagh PV (1989) Human oviductal fluid (hOF) proteins. IV. Evidence for hOF proteins binding to human sperm Ferfility and Sterility 51 89-94

McNutt T, Rogowski L, Vasilatos-Younken R and Killian G (1992) Adsorption of oviductal fluid proteins by the bovine sperm membrane during in vitro capacitation Molecular Reproduction and Development $33 \quad 313-323$

Malayer LR, Hansen PJ and Buhi WC (1988) Secretion of proteins by cultured bovine oviducts collected from estrus through early diestrus Joumal of Experimental Zoology 248 345-353

Moore K and Bondioli KR (1993) Glycine and alanine supplementation of culture medium enhances development of in vitro matured and fertilised cattle embryos Biology of Reproduction 48 833-840

Murray MK (1992) Biosynthesis and immunocytochemical localization of an estrogen-dependent glycoprotein and associated morphological alterations in the sheep ampulla oviduct Biology of Reproduction $47889-902$

Murray MK (1993) An estrogen-dependent glycoprotein is synthesized and released from the oviduct in a temporal and region-specific manner during early pregnancy in the ewe Biology of Reproduction 48 446-453

Nancarrow CD and Hill JL (1994) Coculture, oviduct secretion and the function of oviduct-specific glycoproteins $\mathrm{Cell}$ Biology International is 1105-1114

Nancarrow CD, Hill JL and Connell PJ (1992) Amino acid secretion by the ovine oviduct Proceedings of the Australian Society for Reproductive Biology 2471 (Abstract)

Reuter LM, O'Day-Bowman MB, Mavrogianis PA, Fazleabas AT and Verhage HG (1294) In vitro incubation of golden (Syrian) hamster ovarian oocytes and human sperm with a human oviduct specific glycoprotein Molecular Reprodiction and Development 38 160-169

Salamonsen LA and Nancarrow CD (1994) Cell biology of the oviduct and endometrium. In Molecular Biology of the Female Reproductive System pp 289-328 Ed. JK Findlay. Academic Press, New York

Sendai Y, Abe H, Kikuchi M, Satoh T and Hoshi H (1994) Purification and molecular cloning of bovine oviduct specific glycoprotein Biology of Reproduction $50927-934$

Shur BD and Hall NG (1986) A role for mouse sperm surface galactosyltransferase in sperm binding to egg zona pellucida Journal of Cell Biology 95 574-579

Sutton R, Nancarrow CD, Wallace ALC and Rigby NW (1984a) Identification of an oestrus-associated glycoprotein in oviducal fluid of the sheep Journal of Reproduction and Fertility 72 415-422

Sutton R, Wallace ALC, Engel H and Nancarrow CD (1984b) Binding of sheep oviducal fluid proteins to spermatozoa. In Reproduction in Sheep, Eds DR Lindsay and DT Pearce. Australian Academy of Science, Canberra
Sutton R, Wallace ALC and Nancarrow CD (1985) Characterisation of a glycoprotein in oviductal fluid by twodimensional electrophoresis and lectin binding to protein gel blots Electrophoresis 6 516-520

Sutton R, Nancarrow CD and Wallace ACL (1986) Oestroger and seasonal effects on the production of an oestrusassociated glycoprotein in oviducal fluid of sheep Journal of Reproduction and Fertility 77 645-653

Tervit HR, Whittingham DG and Rowson LEA (1972) Successful culture in vitro of sheep and cattle ova Journal of Reproduc tion and Fertility 30 493-497

Varki A (1993) Biological roles of oligosaccharides: all of the theories are correct Glycabiology $397-130$

Voglmayr JK and Sawyer RF (1986) Surface transformation of ram spermatozoa in uterine, oviduct and cauda epididymal fluids in vitro Joumal of Reproduction and Fertility 78 $315-325$

Walker SK. Heard TM and Scamark RF (1992) In vitro culture of sheep embryos without co-culture; successes and perspectives Theriogenology 37 111-126

Walker SK, Hill JK, Kleeman DO and Nancarrow CD (1995) The effect of amino acids at oviductal flud concentrations or the development of ovine embryos in a defined medium Theriogenology 43345 (Abstract)

Warren CE (1993) Glycosylation Current Opinion in Biotechnology $4596-602$

Wassarman PM (1994) Gamete interactions during mammalian fertilization Theriogenology 41 31-44

Watson AJ, Watson PH, Arcellana-Panilio M, Warnes D, Walker SK, Schultz GA, Armstrong DT and Seamark RF (1994a) A growth factor phenotype map for ovine preimplantation development Biology of Reproduction $\mathbf{5 0}$ 725-733

Watson AJ, Watson PH, Warnes D, Walker SK, Armstrong DT and Seamark RF (I994b) Preimplantation development of in vitro-matured and in vitro-fertilized ovine zygotes: comparison between coculture on oviduct epithelial cell monolayers and culture under low oxygen atmosphere Biology of Reproduction 50 715-724

Wegner CC and Killian GJ (1991) In vitro and in vioo association of an oviduct estrus-associated protein with bovine zona pellucida Molecular Reproduction and Development 29 $77-84$

Wegner CC and Killian GJ (1992) Origin of oestrus-associated glycoproteins in bovine oviductal fluid joumal of Reproduction and Fertility $95841-854$

Yanagimachi R (198I) Mechanisms of fertilization in mammals. In Fertilization and Embryonic Development in Vitro pp 81-182 Eds L Mastroianni and ID Biggers. Plenum, New York 